\title{
Destination Sustainability and Memorable Tourism Experiences
}

\author{
Miguel Ángel Moliner-Tena *(D), Diego Monferrer-Tirado [D, Juan Bautista Ferreres-Bonfill and \\ Rosa M. Rodríguez-Artola
}

Business Administration and Marketing Department, Universitat Jaume I, Castellón 12071, Spain; dmonferr@uji.es (D.M.-T.); ferreres@uji.es (J.B.F.-B.); artola@uji.es (R.M.R.-A.)

* Correspondence: amoliner@uji.es

check for

updates

Citation: Moliner-Tena, M.Á.;

Monferrer-Tirado, D.;

Ferreres-Bonfill, J.B.

Rodríguez-Artola, R.M. Destination Sustainability and Memorable Tourism Experiences. Sustainability 2021, 13, 11996. https://doi.org/ $10.3390 /$ su132111996

Academic Editor: Tim Gray

Received: 23 September 2021

Accepted: 26 October 2021

Published: 29 October 2021

Publisher's Note: MDPI stays neutral with regard to jurisdictional claims in published maps and institutional affiliations.

Copyright: (c) 2021 by the authors. Licensee MDPI, Basel, Switzerland. This article is an open access article distributed under the terms and conditions of the Creative Commons Attribution (CC BY) license (https:/ / creativecommons.org/licenses/by/ $4.0 /)$.

\begin{abstract}
The objective of this paper is to study the relationship between memorable tourism experiences and destination sustainability. Three hypotheses that relate dimensions of sustainability (economic, socio-cultural, and environmental) to memorable tourism experience are considered, based on a review of the literature. A questionnaire designed for that purpose was administered to 1034 tourists who stayed at five rural and sun and beach destinations in Spain. A multigroup analysis with a structural equation model was conducted to establish the differences between both destination types. The results show that destination environmental sustainability influences the memorable tourism experience, though significant differences between rural and sun and beach destinations have been detected. Age plays a moderating role: the younger the tourist the greater the influence of sustainability on memorable tourism experiences.
\end{abstract}

Keywords: memorable experience; sustainability; generation; rural destination; sun and beach destination

\section{Introduction}

The concept of experience is very much present in the tourist sector today [1,2]. Destinations endeavor that their visitors have satisfactory and enriching experiences during their stay; hotels strive to ensure their guests' experience is matchless; restaurants devise experiences that stimulate the five senses; and the leisure offering aspires to provide customers with new, intense, and pleasurable sensations. Presently everyone in tourism is talking about experiences.

However, aside from being positive or negative, experiences can be memorable $[3,4]$. Undoubtedly, attaining a level of experiential excellence brings benefits for both tourists and Destination Marketing Organizations (DMOs) [1,5]. However, what is a memorable experience? Although few studies have explored this concept, it can be said that a memorable experience goes beyond customer satisfaction, since it includes intense, favorable emotions that create an emotional link between visitors and destination $[4,6]$.

In a study on the tourist accommodation industry, Kandampully et al. (2018) reviewed the literature of papers published on tourist experiences [1]. They concluded that despite the importance of the construct, integration of the concept into the principles of tourist accommodation management is very limited.

Moreover, a macro trend today is the concern for sustainability [7,8]. More and more people are worried about the human impact on the environment and take decisions based on their consequences [2,9]. Tourism has also progressed in this area by adapting to the Sustainable Development Goals (SDGs). In academia, increasingly more studies are analyzing the impact of destination sustainability on the tourism experience [2,10-13]. Hanna et al. (2018) consider that given the discrepancies between everyday behaviors related to sustainability and decision-making in tourism, more research is needed to understand how sustainability changes standard tourist behavior [2].

The aim of this paper is to study the extent to which the perceived sustainability of a destination influences the generation of memorable tourism experiences. It is an 
exploratory study that uses a database of 1034 interviews to Facebook and Instagram users who visited five Spanish tourism destinations. The study is divided into four sections. The first outlines the two constructs being studied (memorable tourism experience and destination sustainability) and justifies the hypotheses. The second presents the methodology of the empirical study. The third gives the results, in which the psychometric properties of the scales used are analyzed, and a multigroup structural equation model (SEM) analysis compares rural and sun and beach destinations. Finally, academic and managerial conclusions are presented.

\section{Memorable Tourism Experience}

Pine and Gilmore $(1998,1999)$ define customer experience as a series of events that engage individuals personally [14,15]. This definition fully encompasses tourism products since they are experiential and functional. Stamboulis and Skayannis (2003) emphasized that tourists actively construct their experiences on the ground through their interactions with destinations [16].

Kim, Ritchie, and McCormick (2012) suggested that a memorable tourism experience is selectively built from individual assessments of tourist experiences [3]. Kim (2018) considers that a memorable tourism experience is remembered positively and invoked after the event has occurred [4]. Therefore, memorable tourism experiences are stored in an individual's long-term memory and influence future decisions and word-of-mouth recommendations alike [6,17]. Hanna et al. (2018) maintain that unique and memorable experiences add significant value to consumers and producers, which is an opportunity for the differentiation and competitive advantage of the destination [2].

Visitor satisfaction has traditionally been considered the main argument for tourist loyalty. However, many studies demonstrate a low causal effect of satisfaction on loyalty behavior [1,5]. Kim (2018) found that memorable tourism experiences directly affected behavioral intentions, including that of revisiting the destination and word-of-mouth referrals [4].

Kim, Ritchie, and McCormick (2012) identified seven experiential dimensions that define memorable experience: hedonism, novelty, local culture, refreshment, meaningfulness, involvement, and knowledge [3]. Kim (2018) reduces these dimensions to five in the case of Memorable Tourism Experiences (MTEs): hedonism, refreshment, novelty, meaningfulness, and local culture [4].

Hedonism in travel experience is "pleasurable feelings that excite oneself" [18]. This aspect is related to the five senses that provoke emotional and imaginative perceptions in the consumer [19]. Tourists' desire to see hedonistic experiences, such as excitement and enjoyment, appear to be a key factor in tourism [17].

Novelty seeking is an internal impulse that is triggered within individuals to search for novel information [17]. Novelty seeking involves leaving the comfort zone and taking physical, psychological, and social risks to experience varied, new, and complex feelings. In tourism this dimension of memorable experience is transformed into thrill, change from routine, boredom alleviation, or surprise [20].

Local culture forms part of the essence of tourism since social interactions between visitors and residents is a key aspect of the tourism experience [2,17]. Interaction with local culture, including residents, helps construct unique and memorable tourism experiences [21,22].

Refreshment refers to a change in state of mind. Travelling outside one's usual surroundings creates a feeling of vulnerability which is also extremely liberating [9]. Putting aside everyday problems and disconnecting from the everyday social environment bring mental release, relaxation, and a feeling of freedom that directly influences the importance of the tourism experience [17].

Finally, meaningfulness is the fifth aspect highlighted by Kim (2018) in the review of the MTE construct [4]. Meaningfulness is a personal and private dimension of each person that entails a better knowledge of oneself [17]. Travelling to a tourist destination 
can involve experiences that enable tourists to have more accurate knowledge about themselves, discover their reactions to new situations, face personal growth, and experience self-development. Therefore, tourism experiences that contribute to self-discovery can be described as memorable [3,23].

\section{Memorable Experience and Destination Sustainability}

Sustainability is a current consolidated macro trend that emerged in the last decade $[9,24]$. Respect for labor laws, waste recycling, care for the environment, water and energy consumption, return to local society, and so forth, are concrete aspects related to sustainability that are increasingly present in purchase decisions [2]. The tourism industry has reacted swiftly and has adapted the triple dimensionality of sustainability (economic, social, and environmental) by working to achieve the 17 SDGs.

The most accepted definition of sustainable development stems from the World Commission on Environment and Development (1987), which considers it as development that combines the needs of the present without compromising the ability of future generations to satisfy their own needs [25]. Sustainable development satisfies current tourist and destination demands, while protecting and improving future opportunities. The World Charter for Sustainable Tourism +20 follows this line, upholding as priority objectives the preservation of destination quality and tourism carrying capacity [26].

In this regard, the UN (2012) and UNWTO (2011) consider that sustainable development must be based on three pillars: environmental (the planet), socio-cultural (people), and economic (benefit) $[25,27]$. According to Iniesta-Bonilla et al. (2016), the environmental dimension was the component targeted by the literature on sustainability [28]. It refers to natural capital and the condition of renewable and non-renewable resources [29]. The socio-cultural dimension focuses on human-environment interactions, and the protection of the socio-cultural resources of local communities and destinations, which highlights cultural interaction and the activities required to develop it in the tourist sector. It also covers the creation and improvement of employment, residents' satisfaction, and the upkeep of culture and local heritage [29]. Finally, the economic dimension of sustainability entails satisfying the economic needs of the population, producing maximum results to achieve a high quality of life within existing limitations, as well as the upkeep and optimum use of tourist infrastructures [24,29].

Sustainability involves a balance between the three dimensions and a harmonious coexistence of the interests of the various stakeholders: visitors, industry, environment, and local communities [24]. Reality shows that tourism development has led to an undesirable impact on natural resources, disregard for the interests of some stakeholders (such as residents), and insufficient attention to the problem of climate change [30]. Thus, responsible tourism seeks sustainable development through the coordinated actions of people, businesses, and governments in their quest for a positive impact on economic, social, and environmental surroundings [24].

It is not then about achieving memorable tourism experiences at any price, but about guaranteeing economic, social, and environmental sustainability in a balanced way, i.e., sustainable development is inclusive since it seeks to harmonize the natural surroundings, strengthen the local economy, and improve productive processes by foregrounding local produce [29]. The question is whether sustainability positively or negatively affects the generation of memorable experiences at a destination [2].

Though the relationship between sustainability and tourist experience has received little attention from researchers, some studies have addressed this issue. Lee et al. (2010) established that a hotel's green image generated a more favorable intention to revisit [31]. Benavides et al. (2014) consider that the environmental dimension plays an important role for a hotel because it increases the association with product quality [32]. Moliner et al. (2019) also found a significant relationship between the environmental sustainability of accommodation and tourist experience [33]. 
Everything seems to indicate that a destination with bad sustainability practices will generate unsatisfactory tourism experiences. Tourism research is beginning to focus on this question [25]. This study considers that a destination's three dimensions of sustainability directly influence a tourist's memorable experience. In a conceptual study, Godovykh and Tasci (2010) consider the existence of a series of antecedent situations of the tourism experience, among which they include environmental, cultural, social, and economic macro-environmental factors [34]. Some authors consider that climate change is the key driving force that is transforming the behavior of individuals [2,35]. Nevertheless, this greater awareness about environmental questions does not always lead to the purchase of sustainable products [36]. Solís-Radilla et al. (2019) confirmed that a destination's environmental sustainability indirectly influences the tourism experience through tourist expectations [29]. However, very few studies have analyzed the impact of economic and socio-cultural sustainability on the tourism experience. All the above lead us to raise the following hypotheses.

Hypothesis $\mathbf{1}\left(\mathbf{H}_{\mathbf{1}}\right)$. The economic sustainability of a destination directly influences the memorable tourism experience.

Hypothesis $2\left(\mathbf{H}_{\mathbf{2}}\right)$. The socio-cultural sustainability of a destination directly influences the memorable tourism experience.

Hypothesis $\mathbf{3}\left(\mathbf{H}_{3}\right)$. The environmental sustainability of a destination directly influences the memorable tourism experience.

\section{Methodology}

The general objective of the study is to establish the causal relationship between sustainability and memorable tourism experience. Several specific objectives are also considered: (a) to determine the influence of each of the three dimensions of sustainability on memorable tourism experience, (b) to study the existence of differences between a rural destination and one of sun and sand, and (c) to establish the influence of age as a moderating variable.

We carried out an empirical study based on a survey. Scales validated in the literature were used for measurement instrument design (Table 1). All the items are worded positively and negatively on a five-point Likert scale.

Table 1. Construct measurement scales.

\begin{tabular}{ccc}
\hline Construct & Number of Items & Reference \\
\hline Memorable experience of a destination & One-dimensional: 5 items & {$[4]$} \\
\hline \multirow{3}{*}{ Destination sustainability } & Economic: 4 items & \\
& $\begin{array}{c}\text { Socio-cultural: } 5 \text { items } \\
\text { Environmental: } 5 \text { items }\end{array}$ & {$[28,37]$} \\
\hline
\end{tabular}

Fieldwork was done between November 2020 and March 2021. Given the health restrictions owing to the COVID-19 pandemic that prevented in-person interviews at the destination, the questionnaire was distributed through the social networks Facebook and Instagram. The total sample comprised 1034 valid responses, distributed over five destinations: 397 sun and beach tourists (Peñíscola, Benidorm) and 637 rural tourists (Morella, La Rioja, and Asturias). Participation was conditioned by the individual having stayed at any of the chosen destinations in the last five years. Interviewees could evaluate one destination only.

Descriptive analysis of the data (Table 2) shows several differences between the sample of rural and sun and sand destinations. For age, the difference lies in generations $Y$ and $\mathrm{Z}$ : $\mathrm{Z}$ shows 13 points more for sun and sand destinations, while generation $\mathrm{Y}$ gives 
12 points more for rural ones. As for gender, men score six points more for sun and sand destinations, and women show six points more for rural tourism. No significant differences are apparent regarding studies. Finally, for occupation, students score eight points more at sun and sand destinations; In employment scores 11 points more at rural destinations; and Retired shows five points more at sun and sand destinations.

Table 2. Descriptive statistics of the sample.

\begin{tabular}{|c|c|c|c|c|c|}
\hline GENERATION & Rural & Sun and Sand & GENDER & Rural & Sun and Sand \\
\hline Z (18-26 years) & $14.56 \%$ & $27.45 \%$ & Man & $34.63 \%$ & $40.22 \%$ \\
\hline Y (27-40 years) Millennials & $37.86 \%$ & $25.82 \%$ & Woman & $65.37 \%$ & $59.78 \%$ \\
\hline$X(41-52$ years $)$ & $29.29 \%$ & $25.00 \%$ & NATIONALITY & Frequency & \\
\hline Baby Boom (53-72 years) & $18.12 \%$ & $19.84 \%$ & Spanish & $96.13 \%$ & \\
\hline Silent (>72 years) & $0.16 \%$ & $1.90 \%$ & Foreign & $3.87 \%$ & \\
\hline STUDIES & Rural & Sun and Sand & OCCUPATION & Rural & Sun and Sand \\
\hline No formal schooling & $0 \%$ & $0 \%$ & Student & $9.55 \%$ & $17.93 \%$ \\
\hline Primary school & $2.27 \%$ & $1.36 \%$ & In employment & $74.76 \%$ & $63.04 \%$ \\
\hline Secondary school & $8.09 \%$ & $8.15 \%$ & $\begin{array}{l}\text { Working from } \\
\text { home }\end{array}$ & $5.34 \%$ & $2.72 \%$ \\
\hline $\begin{array}{c}\text { A levels/Certificate of higher } \\
\text { education-HNC }\end{array}$ & $33.17 \%$ & $36.68 \%$ & Retired & $5.34 \%$ & $10.05 \%$ \\
\hline University graduates & $56.47 \%$ & $53.80 \%$ & Unemployed & $5.02 \%$ & $6.25 \%$ \\
\hline
\end{tabular}

Despite these differences, the ANOVA analysis only detected significant differences in age grouped according to generations. Chen and Shoemaker (2014) used the theory of generations to explain the importance of senior tourism in the USA [38]. The sociohistorical environment in which notable events occur impresses upon the youth of groups of individuals who share a similar chronological age, which affects their system of values, personality, tastes, and behaviors. In marketing, generation segmentation (baby boomers, $\mathrm{X}$; millennials, $\mathrm{Y}$ ) is commonplace. Accordingly, age is established as a control variable in the model, given that significant differences were detected for the two variables studied (sustainability and MTE). Individuals were grouped by age cohorts according to the classification by generation: $Z$ generation (18-26 years), Millennials (27-40 years), $X$ generation (41-52 years), Baby Boomers (53-72 years) and Silent generation ( $>72$ years).

Data were analyzed using the statistical program Lavaan package in $\mathrm{R}$.

\section{Analysis and Results}

\subsection{Measurement Reliability and Validity}

Dimensionality, validity, and reliability will be considered for scale validation. The method used to test the theoretical model proposed involves Gerbin and Anderson's (1988) two-step approach [39]. The first stage determines the quality of the measurement scales by a confirmatory factor analysis of all the scales. The second step involves contrasting the relationships of the conceptual model. This approach will allow us to maximize the performance of both the quality of the measurement scale and the results of the relationships raised in the conceptual model.

The models were estimated using the statistical software application Lavaan package in R. First, we studied the dimensionality, reliability, and validity of the scales used (Table 3). We used a confirmatory factor analysis with ordinal data using diagonally weighted least squares estimation and polychoric correlation. 
Table 3. Analysis of dimensionality, reliability, and validity of the measurement scales.

\begin{tabular}{|c|c|c|c|c|}
\hline Items & Median & Mean & $\begin{array}{l}\text { Factor Loading } \\
\text { (Standardized) }\end{array}$ & $t$-Test \\
\hline Memorable tourism experience & \multicolumn{4}{|c|}{$\mathrm{AVE}=0.60 ;$ Composite reliability $=0.90 ;$ Cronbach's alpha $=0.85$} \\
\hline $\begin{array}{l}\text { I had a chance to closely experience the local culture of } \\
\text { that destination area }\end{array}$ & 4 & 4.02 & 0.88 & 0.000 \\
\hline $\begin{array}{l}\text { I experienced something new (e.g., food, activity, etc.) in } \\
\text { this tourism experience }\end{array}$ & 5 & 4.28 & 0.84 & 0.000 \\
\hline I felt revitalized from that tourism experience & 5 & 4.47 & 0.76 & 0.000 \\
\hline I really enjoyed that tourism experience & 5 & 4.55 & 0.77 & 0.000 \\
\hline $\begin{array}{l}\text { I learned something about myself from that } \\
\text { tourism experience }\end{array}$ & 4 & 3.90 & 0.75 & 0.000 \\
\hline Economic sustainability & \multicolumn{4}{|c|}{$\mathrm{AVE}=0.59 ;$ Composite reliability $=0.81 ;$ Cronbach's alpha $=0.71$} \\
\hline $\begin{array}{l}\text { The staff seemed to be well-trained } \\
\text { and prepared }\end{array}$ & 4 & 4.19 & 0.80 & 0.000 \\
\hline The stores sold local products & 4 & 4.09 & 0.79 & 0.000 \\
\hline $\begin{array}{l}\text { The infrastructure and basic services at this destination } \\
\text { were good }\end{array}$ & 4 & 4.30 & 0.71 & 0.000 \\
\hline Socio-cultural sustainability & \multicolumn{4}{|c|}{$\mathrm{AVE}=0.58 ;$ Composite reliability $=0.87 ;$ Cronbach's alpha $=0.83$} \\
\hline $\begin{array}{l}\text { The protection and conservation of heritage } \\
\text { were encouraged }\end{array}$ & 4 & 4.07 & 0.85 & 0.000 \\
\hline $\begin{array}{l}\text { The cultural and social development of the local } \\
\text { community was promoted }\end{array}$ & 4 & 4.07 & 0.86 & 0.000 \\
\hline $\begin{array}{l}\text { A commitment to social projects was apparent at } \\
\text { this destination }\end{array}$ & 4 & 3.58 & 0.81 & 0.000 \\
\hline $\begin{array}{l}\text { Employment discrimination for reasons of gender, race, } \\
\text { nationality, etc., was not observed }\end{array}$ & 4 & 4.13 & 0.64 & 0.000 \\
\hline The infrastructure had been adapted for disabled people & 4 & 3.78 & 0.60 & 0.000 \\
\hline Environmental sustainability & \multicolumn{4}{|c|}{$\mathrm{AVE}=0.65 ;$ Composite reliability $=0.90 ;$ Cronbach's alpha $=0.86$} \\
\hline $\begin{array}{c}\text { At this destination the environment was respected and } \\
\text { cared for }\end{array}$ & 4 & 4.03 & 0.86 & 0.000 \\
\hline Energy and water saving was encouraged & 4 & 3.73 & 0.85 & 0.000 \\
\hline $\begin{array}{l}\text { Rubbish and waste were reduced, reused, } \\
\text { and recycled }\end{array}$ & 4 & 3.68 & 0.78 & 0.000 \\
\hline Ecological products were used & 3 & 3.42 & 0.78 & 0.000 \\
\hline The level of contamination and bad smells was good & 4 & 4.02 & 0.75 & 0.000 \\
\hline
\end{tabular}

The probability associated with chi-squared reaches a value below 0.05 , indicating an acceptable overall fit of the scale [40]. Convergent validity is demonstrated because the factor loadings are significant and higher than 0.5 [41-43], and because the average variance extracted (AVE) for each of the factors is higher than 0.5 [44]. As for the reliability of the scale, the indices of composite reliability of each of the dimensions obtained are higher than 0.6 [42].

Table 4 shows the discriminant validity of the construct considered, evaluated by AVE [44]. A construct must share more variance with its indicators than with other constructs in the model. This occurs when the square root of the AVE between each pair of factors is higher than the estimated correlation between those factors, as occurs here, 
therefore ratifying its discriminant validity. As a result, the first step was successfully completed and determined the good quality of the measurement scales used.

Table 4. Discriminant validity analysis.

\begin{tabular}{|c|c|c|c|c|}
\hline & $\begin{array}{c}\text { Memorable } \\
\text { Tourism Experience }\end{array}$ & $\begin{array}{c}\text { Economic } \\
\text { Sustainability }\end{array}$ & $\begin{array}{l}\text { Socio-Cultural } \\
\text { Sustainability }\end{array}$ & $\begin{array}{l}\text { Environmental } \\
\text { Sustainability }\end{array}$ \\
\hline Memorable tourism experience & 0.77 & & & \\
\hline Economic Sustainability & $0.49 *$ & 0.77 & & \\
\hline Socio-cultural sustainability & 0.44 * & 0.56 * & 0.76 & \\
\hline Environmental sustainability & $0.44 *$ & 0.53 * & $0.65 *$ & 0.81 \\
\hline
\end{tabular}

Below the diagonal: correlations estimated between the factors. Diagonal: square root of AVE. ${ }^{*} p<0.05$ (Pearson).

\subsection{Hypotheses Testing}

A specific objective of the research is to establish the causal relationship between the three dimensions of sustainability and memorable tourism experience. Simultaneously, a second specific objective is considered to determine whether these causal relationships are the same for a rural and a sun and sand destination.

The sample consists of two clearly differentiated subsamples: rural tourism and sun and beach tourism. The ANOVA detected significant differences of means in all the variables. Given this sample structure the most appropriate statistical technique is a multigroup analysis to determine whether there is a general pattern of behavior or, conversely, whether the pattern differs between both types of destination.

Multigroup analysis begins with the estimation of two models: one in which all parameters are allowed to differ between groups (free model), and one in which all parameters are fixed to those obtained from analysis of the pooled data across groups (constrained model). If the two models are not significantly different (ANOVA), and the latter fits the data well, it can be assumed that there is no variation in the path coefficients by group, and the multigroup approach is not necessary. In this case, the output from the constrained model would be reported. If they are significantly different, then the exercise shifts towards understanding which paths are the same and which are different. This is achieved by sequentially constraining the coefficients of each path and re-fitting the model.

A third specific objective is to determine whether age is a moderating variable of the relationship between the three dimensions of sustainability and memorable tourism experience. To that end, age is established as a control variable.

After the application of multigroup analysis, the comparison of the free and constrained models by ANOVA revealed significant differences, indicating that the coefficients varied between the two groups (Table 5). The introduction of constraints to identify the paths that vary between groups shows that all the paths present significant differences, which implies that the free model best represents data behavior.

Table 5. ANOVA free model and constrained model in multigroup SEM analysis.

\begin{tabular}{cccccccc}
\hline \multicolumn{8}{c}{ Chi-Squared Difference Test } \\
\hline & Df & AIC & BIC & Chi-sq & diff Df & diff & Pr(>Chi-sq) \\
\hline Free model & 286 & 39,309 & 39,941 & 1115.0 & 100.33 & 18 & $1.926 \mathrm{e}-13^{*}$ \\
\hline Constrained model & 304 & 39,373 & 39,917 & 1215.4 & 10 \\
\hline \multicolumn{7}{c}{ Signif. code: ${ }^{* * \prime} 0.001}$. &
\end{tabular}

Table 6 shows the final result of the multigroup analysis. Model adjustment is acceptable since the $\chi^{2}$, SRMR, and RMSEA present within-standard values. 
Table 6. Results multigroup SEM.

\begin{tabular}{cccc}
\hline \multicolumn{1}{c}{ Path } & Parameter & $t$ & Results \\
\hline Rural Destination $\mathrm{R}^{2}=0.46$ & & & \\
\hline Economic sustainability $\rightarrow$ Memorable tourism experience & 0.45 & 0.000 & Supported \\
\hline Socio-cultural sustainability $\rightarrow$ Memorable tourism experience & -0.10 & 0.478 & Not supported \\
\hline Environmental sustainability $\rightarrow$ Memorable tourism experience & 0.36 & 0.007 & Supported \\
\hline Generation $\rightarrow$ Memorable tourism experience & -0.03 & 0.363 & Not supported \\
\hline Sun And Beach Destination $\mathrm{R}^{2}=0.48$ & 0.30 & 0.120 & Not supported \\
\hline Economic sustainability $\rightarrow$ Memorable tourism experience & 0.15 & 0.455 & Not supported \\
\hline Environmental sustainability $\rightarrow$ Memorable tourism experience & 0.26 & 0.025 & Supported \\
\hline Generation $\rightarrow$ Memorable tourism experience & -0.19 & 0.000 & Supported \\
\hline
\end{tabular}

Model fit indices: $\chi^{2}=1115.358 ; \mathrm{df}=286, \chi^{2} / \mathrm{df}=3.9 ; p$ value $=0.000 ; \mathrm{SRMR}=0.043 ;$ RMSEA $=0.075 ; \mathrm{GFI}=0.988 ;$ AGFI $=0.982$; $\mathrm{CFI}=0.912 ; \mathrm{IFI}=0.913$.

In the case of a rural destination, the economic and environmental sustainability of the tourist destination exerts significant influence on the memorable tourism experience. The control variable (generation) exerts no significant influence.

In the case of the sun and beach destination, only the environmental sustainability of the destination has a significant influence on the memorable tourism experience. In this case, the influence of the control variable is significant, such that the older the visitor the lesser the influence of environmental sustainability on the memorable tourism experience (the ANOVA indicates the significant difference appears among millennials and baby boomers).

\section{Discussion and Conclusions}

\subsection{Theoretical Implications and Contributions}

The objective of this paper is to analyze the influence of sustainability on a destination in generating a memorable tourism experience. The main conclusion is that the memorable experience depends on destination sustainability. Nevertheless, general patterns of behavior cannot be extracted since they depend on the type of destination [45].

A specific objective is to determine whether these causal relationships are the same for a rural and a sun and sand destination. In the case of a rural destination, economic $(0.45)$ and environmental (0.36) sustainability significantly influence memorable experience. Rural tourists value the impact of tourism on the quality of life of the tourist destination. They value how staff are treated, the use of local products, and the degree of development of infrastructure and basic services at the destination. Because they are far from urban centers, rural destinations usually suffer from a lower degree of economic development. Additionally significant in the memorable experience of a rural destination is environmental sustainability. Tourists value respect and care for the environment, energy and water saving, recycling, the use of ecological products, and the level of contamination and bad smells.

In the case of sun and sand destinations, the memorable tourism experience is only influenced by environmental sustainability (0.26). It seems that the impact of mass sun and beach tourism on the tourism experience is such that the greater the perception of environmental sustainability the more positive the memorable experience. The control variable is significant in this case, so that the older the tourists the lower the influence of environmental sustainability on the memorable experience of sun and beach tourists.

Therefore, environmental sustainability is the only dimension that exerts significant influence on the memorable tourism experience (both for rural and sun and beach tourism). Conversely, socio-cultural sustainability exerts no significant influence on either type 
of tourism. Economic sustainability only influences rural destinations, and the control variable, age, is only significant for sun and beach destinations.

From these results we can conclude that $\mathrm{H}_{3}$ is met, but not $\mathrm{H}_{1}$ or $\mathrm{H}_{2}$. Multigroup analysis establishes that treating each sample separately (rural and sun and sand) provides a better representation of data behavior. The only causal relationship reproduced in both groups is that environmental sustainability influences memorable tourism experience $\left(\mathrm{H}_{3}\right)$. This result concurs with studies [31-33], which establish that environmental sustainability significantly influences tourist experiences. Economic sustainability only has a significant influence on rural destinations ( $\mathrm{H}_{1}$ is partially met), while socio-cultural sustainability's influence on memorable tourism experience is not significant in either of the two groups.

A specific objective of the study was to analyze the moderating role of age and generations. The results show the existence of this effect, in that sustainability exerts more influence on the memorable tourism experience of younger tourists. More specifically significant differences have been identified between the generations of baby boomers and millennials. The latter are more sensitive to sustainability because of a greater awareness of climate change, which is an event of their generation. It is noteworthy that few empirical tourism studies based on the theory of generations have been done [38].

One remarkable aspect of this study is that the sample was obtained during the COVID-19 pandemic, during which tourism suffered the worst crisis in its history. The pandemic has had a considerable socio-cultural, economic, and psychological impact on different tourism stakeholders [46]. Consumers, for example, lend increasing importance to health and safety. The implication for tourism has been a preference for tourist resorts that are less crowded and closer to nature [47]. The impact of harrowing tourist experiences broadcast by the media has led to a fear of travelling [46]. Nevertheless, in the final stage of the pandemic, with progress made by vaccination campaigns, tourists appear eager to fraternize and socialize after many months of restricted social contact. This phenomenon is much more pronounced among the younger generations. Undoubtedly these sociological changes affect the assessment of tourism experience and the relevance of environmental aspects [46]. However, we cannot infer that this circumstance has affected this study because the tourists interviewed evaluated their stays of the last five years. Furthermore, it is still too early to assess the structural effects of COVID-19 and the various stakeholders capacity for resilience.

This study makes three contributions to the state of art. First, it scrutinizes the impact of the sustainability of a tourist destination on generating memorable tourism experiences. Although sustainability has been the subject of academic attention in recent years, to date its influence on generating memorable experiences has been little studied [1]. Environmental sustainability is relevant, while economic sustainability is only significant at a rural destination.

A second contribution is that the impact of sustainability on a memorable tourism experience depends on the type of destination. Although environmental sustainability is a determining factor in both types of destination studied, economic sustainability only has an impact on rural destinations. Conversely, socio-cultural sustainability is not significant in either type of destination.

A third contribution is the role played by age. The generations have a different perception of the importance of sustainability. Although age is only significant for sun and beach destinations, the results show that younger generations (millennials) are the most sensitive, while baby boomers are less so. The theory of generations is a type of analysis rarely applied in tourism [38].

\subsection{Managerial Implications}

A memorable tourism experience (MTE) is based on five dimensions: hedonism, refreshment, novelty, meaningfulness, and local culture. DMOs should be market oriented and design their services to generate agreeable, stimulating feelings, novelty, surprise, contact with local culture, mental release, relaxation, a feeling of freedom, and improved 
self-awareness [2]. These dimensions of the experience differ from the traditional parameters of service design, where technical and functional quality are the most representative elements. This change in paradigm entails foregrounding tourists' feelings and emotions to generate a permanent impact on visitors' long-term memory, leading to a higher probability of them repeating their visit and/or recommending the destination.

In addition, tourism destinations must manage economic, socio-cultural, and environmental sustainability because it is one of the antecedents that influences the generation of MTEs. In the case of rural destinations, it appears to be important to show visitors that significant economic development has been achieved. Thus, infrastructure and public services must be good; staff must be well-trained; and local products must be offered. It is equally important to display the destination's degree of environmental sustainability through energy and water saving campaigns, recycling actions, provision of ecological products, and low levels of contamination and bad smells.

In the case of sun and sand destinations, caring for the environment is crucial, perhaps because they entail a type of mass tourism, which has a great impact on sustainability. Visitors to sun and beach destinations must perceive DMOs to be carrying out campaigns that show care and respect for the environment. In this case, consideration must be given to the fact that age plays an important role because younger generations have a higher regard for environmental sustainability than their elders.

Some limitations of the study must be pointed out. First, it would be advisable to examine another type of tourist destination (cultural or urban), to analyze whether the three dimensions of sustainability have an impact on MTEs.

A second limitation concerns cross-sectional data that represent a reality at a given moment. Replicating the fieldwork at another time would be very useful. Building a time series by administering the questionnaire in consecutive years would make it easier to observe how the model's explanatory capacity evolves.

In a future study we plan to segment the sample by generation, to explore whether there are specific patterns of behavior in each generation, irrespective of destination type.

Author Contributions: Conceptualization, M.Á.M.-T., D.M.-T., J.B.F.-B. and R.M.R.-A.; methodology, M.Á.M.-T., D.M.-T., J.B.F.-B. and R.M.R.-A.; software, M.Á.M.-T., D.M.-T., J.B.F.-B. and R.M.R.-A.; validation, M.Á.M.-T., D.M.-T., J.B.F.-B. and R.M.R.-A.; formal analysis, M.Á.M.-T., D.M.-T., J.B.F.-B. and R.M.R.-A.; investigation, M.Á.M.-T., D.M.-T., J.B.F.-B. and R.M.R.-A.; resources, M.Á.M.-T., D.M.-T., J.B.F.-B. and R.M.R.-A.; data curation, M.Á.M.-T., D.M.-T., J.B.F.-B. and R.M.R.-A.; writingoriginal draft preparation, M.Á.M.-T., D.M.-T., J.B.F.-B. and R.M.R.-A.; writing-review and editing, M.Á.M.-T., D.M.-T., J.B.F.-B. and R.M.R.-A.; visualization, M.Á.M.-T., D.M.-T., J.B.F.-B. and R.M.R.-A.; supervision, M.Á.M.-T., D.M.-T., J.B.F.-B. and R.M.R.-A.; project administration, M.Á.M.-T., D.M.-T., J.B.F.-B. and R.M.R.-A.; funding acquisition, M.Á.M.-T., D.M.-T., J.B.F.-B. and R.M.R.-A. All authors have read and agreed to the published version of the manuscript.

Funding: This work is supported by the AICO/2020/074 project of the Generalitat Valenciana (Spain) for consolidated research groups.

Institutional Review Board Statement: Not applicable.

Informed Consent Statement: Not applicable.

Data Availability Statement: Not applicable.

Conflicts of Interest: There is no conflict of interest.

\section{References}

1. Kandampully, J.; Zhang, T.; Jaakkola, E. Customer experience management in hospitality: A literature synthesis, new understanding and research agenda. Int. J. Contemp. Hosp. Manabement 2018, 30, 21-56. [CrossRef]

2. Hanna, P.; Font, X.; Scarles, C.; Weeden, C.; Harrison, C. Tourist destination marketing: From sustainability myopia to memorable experiences. J. Destin. Mark. Manag. 2018, 9, 36-43. [CrossRef]

3. Kim, J.H.; Ritchie, J.R.B.; McCormick, B. Development of a scale to measure memorable tourism experiences. J. Travel Res. 2012, 51, 12-25. [CrossRef] 
4. Kim, J.H. The impact of memorable tourism experiences on loyalty behaviors: The mediating effects of destination image and satisfaction. J. Travel Res. 2018, 57, 856-870. [CrossRef]

5. Taheri, B.; Gannon, M.J.; Kesgin, M. Visitors' perceived trust in sincere, authentic, and memorable heritage experiences. Serv. Ind. J. 2020, 40, 705-725. [CrossRef]

6. Bigné, E.; Fuentes-Medina, M.L.; Morini-Marrero, S. Memorable tourist experiences versus ordinary tourist experiences analysed through user-generated content. J. Hosp. Tour. Manag. 2020, 45, 309-318. [CrossRef]

7. Vellecco, I.; Mancino, A. Sustainability and tourism development in three Italian destinations: Stakeholders' opinions and behaviours. Serv. Ind. J. 2010, 30, 2201-2223. [CrossRef]

8. Arici, H.E.; Uysal, M. Leadership, green innovation, and green creativity: A systematic review. Serv. Ind. J. 2021, 1-41. [CrossRef]

9. Han, H. Consumer behavior and environmental sustainability in tourism and hospitality: A review of theories, concepts, and latest research. J. Sustain. Tour. 2021, 29, 1021-1042. [CrossRef]

10. Ruhanen, L.; Weiler, B.; Moyle, B.D.; McLennan, C.-L.J. Trends and petterns in sustainable tourism research: A 25-year bibliometric análisis. J. Sustain. Tour. 2015, 23, 517-535. [CrossRef]

11. Niñerola, A.; Sánchez-Rebull, M.V.; Hernández-Lara, A.B. Tourism research on sustainability: A bibliometric análisis. Sustainability 2019, 11, 1377. [CrossRef]

12. Font, X.; McCabe, S. Sustainability and marketing in tourism: Its contexts, paradoxes, approaches, challenges and potential. J. Sustain. Tour. 2017, 25, 869-883. [CrossRef]

13. Agapito, D.; Valle, P.; Mendes, J. The sensory dimension of tourist experiences: Capturing meaningful sensory-informed themes in Southwest Portugal. Tour. Manag. 2014, 42, 224-237. [CrossRef]

14. Pine, B.J., II; Gilmore, J.H. Welcome to the Experience Economy. Harv. Bus. Rev. 1998, 76, 97-105.

15. Pine, B.J., II; Gilmore, J.H. The Experience Economy; Harvard Business School Press: Boston, MA, USA, 1999.

16. Stamboulis, Y.; Skayannis, P. Innovation strategies and technology for experience-based tourism. Tour. Manag. 2003, 24, 35-43. [CrossRef]

17. Coudounaris, D.N.; Sthapit, E. Antecedents of memorable tourism experience related to behavioral intentions. Psychol. Mark. 2017, 34, 1084-1093.

18. Kim, J.-H.; Ritchie, J.R.; Tung, V.W.S. The effect of memorable experience on behavioral intentions in tourism: A structural equation modeling approach. Tour. Anal. 2010, 15, 637-648. [CrossRef]

19. Holbrook, M.B.; Hirschman, E.C. The experiential aspects of consumption: Consumer, fantasies, feelings and fun. J. Consum. Res. 1982, 9, 132-140. [CrossRef]

20. Lee, T.-H.; Crompton, J. Measuring novelty seeking in tourism. Ann. Tour. Res. 1992, 19, 732-751. [CrossRef]

21. Kim, J.-H. The antecedents of memorable tourism experiences: The development of a scale to measure the destination attributes associated with memorable experiences. Tour. Manag. 2014, 44, 34-45. [CrossRef]

22. Croce, E.; Perri, G. Supply operators in the food and wine tourism industry. In Food and Wine Tourism: Integrating Food, Travel and Territory; CABI: Oxfordshire, UK, 2010; pp. 137-156.

23. Tsiotsou, R.H.; Goldsmith, R.E. Target marketing and its application to tourism. In Strategic Marketing in Tourism Services; Emerald Group Publishing: Bingley, UK, 2012; pp. 3-15.

24. Mihalic, T.; Mohamadi, S.; Abbasi, A.; Dávid, L.D. Mapping a sustainable and responsible tourism paradigm: A bibliometric and citation network análisis. Sustainability 2021, 13, 853. [CrossRef]

25. WCED. Report of the World Commission on Environment and Development: Our Common Future; Oxford University Press: Oxford, UK, 1987.

26. Responsible Tourism Institute. Word Charter for Sustainable Tourism +20; Word Summit on Sustainable Tourism: Vitoria-Gasteiz, Spain, 2015.

27. United Nations. Outcome of the conference. In Proceedings of the RIO+20 United Nations Conference on Sustainable Development, Rio de Janeiro, Brazil, 20-22 June 2012. Available online: http:/ / www.uncsd2012.org/thefuturewewant.html (accessed on 14 October 2016).

28. Iniesta-Bonillo, M.A.; Sánchez-Fernández, R.; Jiménez-Castillo, D. Sustainability, value and satisfaction: Model testing and cross-validation in tourist destinations. J. Bus. Res. 2016, 69, 5002-5007. [CrossRef]

29. Solís-Radilla, M.A.; Hernández-Lobato, L.; Callarisa-Fiol, L.J.; Pastor-Durán, H.T. The importance of sustainability in the loyalty to a tourist destination through the management of expectations and experiences. Sustainability 2019, 11, 4132. [CrossRef]

30. Milano, C.; Novelli, M.; Cheer, J.M. Overtourism and degrowth: A social movements perspective. J. Sustain. Tour. 2019, 27, 1857-1875. [CrossRef]

31. Lee, J.; Hsu, L.; Han, H.; Kim, Y. Understanding how consumers view green hotels: How a hotel's green image can influence behavioural intentions. J. Sustain. Tour. 2010, 18, 901-914. [CrossRef]

32. Benavides-Velasco, C.A.; Quintana-García, C.; Marchante-Lara, M. Total quality management, corporate social responsibility and performance in the hotel industry. Int. J. Hosp. Manag. 2014, 41, 77-87. [CrossRef]

33. Moliner, M.A.; Monferrer, D.; Estrada, M.; Rodrígue, R.M. Environmental sustainability and the hospitality customer experience: A study in tourist accommodation. Sustainability 2019, 11, 5279. [CrossRef]

34. Godovykh, M.; Tasci, D.A. Customer experience in tourism: A review of definitions, components, and measurements. Tour. Manag. Perspect. 2020, 35, 100694. [CrossRef] 
35. Scott, D.; Gössling, S.; Hall, M. Tourism and Climate Change: Impacts, Adaptation and Mitigation; Routledge: Abingdon, UK, 2012.

36. Miller, G.; Rathouse, K.; Scarles, C.; Holmes, K.; Tribe, J. Public understanding of sustainable tourism. Ann. Tour. Res. 2010, 37, 627-645. [CrossRef]

37. Suárez-Cebador, M.; Rubio-Romero, J.C.; Pinto-Contreiras, J.; Gemar, G. A model to measure sustainable development in the hotel industry: A comparative study. Corp. Soc. Responsib. Environ. Manag. 2018, 25, 722-732. [CrossRef]

38. Chen, S.C.; Shoemaker, S. Age and cohort effects: The american senior tourism market. Ann. Tour. Res. 2014, 48, 58-75. [CrossRef]

39. Gerbing, D.W.; Anderson, J.C. An updated paradigm for scale development incorporating unidimensionality and its assessment. J. Mark. Res. 1988, 25, 186-192. [CrossRef]

40. Jöreskog, K.G.; Sörbom, D. LISREL 8: Structural Equation Modeling with the SIMPLIS Command Language; Scientific Software International: Chicago, IL, USA, 1996.

41. Bagozzi, R.P. Performance and satisfaction in an Industrial salesforce: An examination of their antecedents and simultaneity. J. Mark. 1980, 44, 65-77. [CrossRef]

42. Bagozzi, R.P.; Yi, Y. On the evaluation of structural equation models. J. Acad. Mark. Sci. 1988, 16, 74-94. [CrossRef]

43. Hair, J.F., Jr.; Black, W.C.; Babin, B.J.; Anderson, R.E.; Tatham, R.L. Multivariate Data Analysis, 6th ed.; Prentice Hall: Upper Saddle River, NJ, USA, 2006.

44. Fornell, C.; Larcker, D. Structural equation models with unobservable variables and measurement error. J. Mark. Res. 1981, 18, 39-50. [CrossRef]

45. Lee, T.H.; Jan, F.-H. The influence of recreation experience and environmental attitude on the environmentally responsible behavior of community-based tourists in Taiwan. J. Sustain. Tour. 2015, 23, 1063-1094. [CrossRef]

46. Sigala, M. Tourism and COVID-19: Impacts and implications for advancing and resetting industry and research. J. Bus. Res. 2020, 117, 312-321. [CrossRef]

47. Ioannides, D.; Gyimóthy, S. The COVID-19 crisis as an opportunity for escaping the unsustainable global tourism path. Tour. Geogr. 2020, 22, 624-632. [CrossRef] 